\title{
Havia uma Rosa e uma Vitória na representação pictórica da história de Mato Grosso
}

\author{
There was a Rosa and a Vitória in the pictorial representation of the history of Mato \\ Grosso
}

\begin{abstract}
Resumo: A historiografia é impregnada dos sentidos da universalidade do masculino e do branco. Para desconstruir ou questionar as violências, que são também imagéticas, apresento parte de uma pesquisa que toma como fonte o acervo dos quadros históricos de Moacyr Freitas - arquiteto e desenhista, autor de telas que representam fatos da história de Mato Grosso. Os quadros estão no Museu Histórico de Cuiabá e alguns foram reproduzidos em livro didático. As duas pinturas selecionadas para a construção deste artigo são as únicas do acervo pesquisado que trazem mulheres como protagonistas: $A$ paz com os Guayacurus e Rosa Boróro. Por intermédio dessas obras, é possível desenvolver debates étnico-raciais e de gênero.
\end{abstract}

Palavras-chave: quadros históricos, gênero, raça/etnia

\section{Introdução}

Rosa e Vitória são nomes que ficaram registrados em algumas citações literárias e em quadros históricos de Moacyr Freitas. Duas mulheres cujos nomes originais ficaram esquecidos ou foram adulterados pelos colonizadores brancos. Uma mulher índia e outra negra, únicas protagonistas em episódios da história de Mato Grosso representadas no conjunto das 60 telas do acervo pesquisado. Os nomes são praticamente licenças poéticas para este texto, que questiona a parca visibilidade étnico-racial que mulheres índias e negras tiveram na historiografia mato-grossense, a exemplo da história do Brasil.

Desde cedo na escola e desde o século XIX, aprende-se uma história do Brasil que diz ser a população brasileira formada pela miscigenação de três raças: branca, negra e índia. Se não bastasse esse resumo étnico ${ }^{1}$, existe uma hierarquia na qual o branco foi considerado

\footnotetext{
* Doutora pela Universidade Federal de Santa Catarina (UFSC). Professora do Departamento de História, Programa de Pós-graduação em História e do Programa Profissional em Ensino de História da Universidade Federal de Mato Grosso (UFMT). E-mail: anamariamarques.ufmt@gmail.com.
} 
superior (o colonizador), o negro inferior - por isso escravizado (colonizado) -, e o índio uma espécie de não-sujeito, um selvagem a ser domesticado, cristianizado ou civilizado. $\mathrm{Na}$ interseção dessas categorias, não se considerou que mulheres (brancas, negras ou indígenas) possuem suas diferenças na relação com seus pares étnicos e com as outras etnias. As relações inter-raciais ou interétnicas foram construídas de diferentes maneiras entre homens e mulheres de diferentes etnias e estratos sociais.

Algumas feministas negras têm alertado para a tendência perigosa de homogeneizar as categorias. Para María Lugones (2014, p. 22), “el eje de colonialidad no es suficiente para dar cuenta de todos los aspectos del género"2.

En la intersección entre "mujer" y "negro" hay una ausencia donde debería estar la mujer negra precisamente porque ni "mujer" ni "negro' la incluyen. La intersección nos muestra un vacío. Por eso, una vez que la interseccionalidad nos muestra lo que se pierde, nos queda por delante la tarea de reconceptualizar la lógica de la intersección para, de ese modo, evitar la separabilidad de las categorías dadas y el pensamiento categorial. Solo al percibir género y raza como entretramados o fusionados indisolublemente, podemos realmente ver a las mujeres de color. Esto implica que el término "mujer" en si, sin especificación de la fusión, no tiene sentido o tiene un sentido racista, ya que la lógica categorial históricamente ha seleccionado solamente el grupo dominante, las mujeres burguesas blancas heterosexuales y por lo tanto ha escondido la brutalizacion, el abuso, la deshumanización que la colonialidad del género implica ${ }^{3}$ (LUGONES, 2014, p. 21).

Não é possível, então, achar que na história que inclui índios e negros - já que uma história de brancos e para brancos é mais recorrente -, as mulheres negras e índias estejam contempladas nas suas relações de diferenças com homens, sejam eles iguais ou diferentes em

etnias. É difícil falar em iguais. Todavia, existem experiências comuns entre mulheres, e existem também os fatores que diferenciam tratamentos, reconhecimentos e identificações de mulheres negras e índias que chegam à - ou beiram a - invisibilidade delas.

\section{Sobre gênero}

No contexto moderno de produção de conhecimento, a História pelo viés positivista foi escrita dando "destaque a personagens, em geral masculinos, que tinham de alguma forma participado dos governos e/ou guerras", lembra Joana Maria Pedro (2005, p. 84), uma história na qual o lugar das mulheres era secundário. Elas só eram incluídas quando ocupavam, eventualmente, o trono ou a "face oculta" do poder: as rainhas e princesas, as guerreiras no sentido literal, a exemplo de Anita Garibaldi - considerada heroína de dois mundos porque lutou na Revolução Farroupilha pela independência do Brasil e na Itália, no processo de 
unificação - ou as inúmeras mulheres que tiveram atuação preponderante "ao lado" ou "por trás" de homens considerados "importantes". Esses/as personagens heroicos/as há muito atraem atenção para as representações imagéticas, ou seja, significados expressos em forma de imagens, que podem ser literárias ou pictóricas, ou, ainda, ambas inspiradas entre si.

Caso curioso foi o de Soldado Medeiros, que nasceu Maria Quitéria (Figura 1) no sertão da Bahia em 1792. Em 1822, às escondidas do pai, alistou-se no regimento de artilharia do exército que arregimentava voluntários para as batalhas de independência do Brasil. Entrou para o exército fazendo-se passar por homem, e só descobriram que se tratava de uma mulher porque o próprio pai a teria denunciado. Mas era tarde, pois já havia recebido honras por liderar e vencer batalhas como "Soldado Medeiros". Então, depois que sua identidade foi revelada, mandaram confeccionar um saiote para diferenciá-la dos soldados homens (VALIM, 2013).

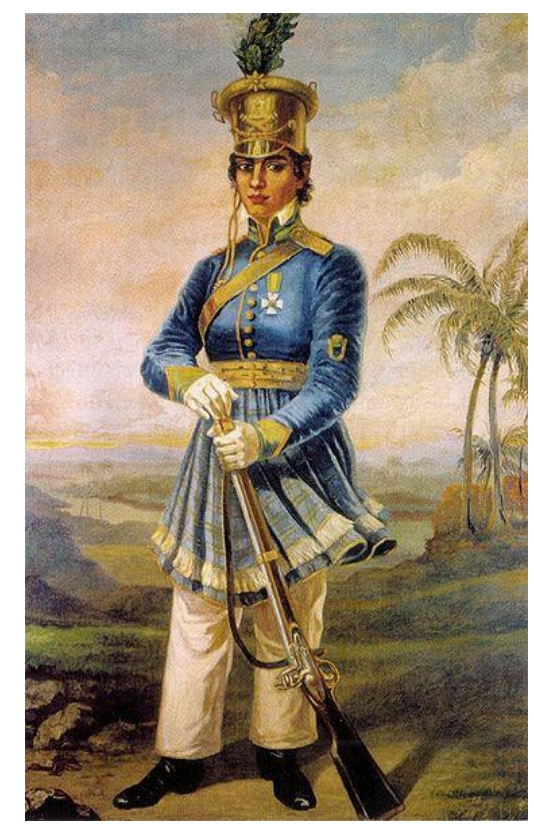

Figura 1 - Maria Quitéria, por Domenico Failutti (1919). Domínio público.

Questionar a produção historiográfica, o silenciamento das mulheres ou o destaque só quando elas mostram capacidade de ser como homens ainda é uma herança historiográfica que busca valorizar as mulheres, numa aproximação do que era ambicionado pelas feministas da chamada primeira onda "da igualdade". Nessa primeira fase do feminismo, era recorrente as mulheres almejarem ser como homens, pois só a eles era reservado o direito à vida pública, a certos trabalhos e mesmo ao uso de calças. Vale ressaltar que, embora esse feminismo datado de final do século XIX e início do XX tivesse essas características, as reivindicações 
partiam, sobretudo, de mulheres brancas de classe média. As mulheres pretas e índias ou já estavam há muito fazendo parte da vida pública (das ruas e em trabalhos informais), ou continuariam ainda muito tempo depois alijadas das oportunidades para alcançar cidadania. $\mathrm{Na}$ "segunda onda", aquela que se convencionou contextualizar-se nos movimentos dos anos 1960 até 1980, muitas mulheres reivindicaram o direito à diferença. As lutas pelo direito de tomar decisões a respeito de seu corpo e do que dele origina - a procriação/maternidade ou não (aborto ou métodos contraceptivos femininos) - estavam na pauta da militância feminista dos anos 70 e, sobretudo, dos $80^{4}$.

Para marcar a importância das abordagens feministas, Margareth Rago (1998, p. 2324, grifos da autora) salienta:

O feminismo não apenas tem produzido uma crítica contundente ao modo de produção do conhecimento científico, como também propõe um modo alternativo de operação e articulação nesta esfera. Além disso, se considerarmos que as mulheres trazem uma experiência histórica e cultural diferenciada da masculina, ao menos até o presente, uma experiência que várias já classificaram como das margens, da construção miúda, da gestão do detalhe, que se expressa na busca de uma nova linguagem, ou na produção de um contradiscurso, é inegável que uma profunda mutação vem se processando, também, na produção do conhecimento científico.

Na lógica dicotômica da normatividade, ou se é hétero ou homo (para sexualidade); ou pobre ou rico (para classe); ou branco ou negro (para raça/cor); ou jovem ou velho, criança ou adulto (para idade). Esse binarismo, que ainda é hegemônico na nossa cultura social, supõe existir um lado "forte", logo "superior", em oposição ao lado "fraco", "inferior". Muitos autores concordam ser essa uma lógica dominante. Tomaz Tadeu da Silva (2000, p. 82-83) reforça:

A afirmação da identidade e a marcação da diferença implicam, sempre, as operações de incluir e excluir. [...] dizer "o que somos" significa também dizer "o que não somos". [...] A força homogeneizadora da identidade normal é diretamente proporcional à sua invisibilidade.

Historicamente, o binarismo, com a consequente invisibilidade do lado considerado em desvantagem, provocou um fosso que não só dividiu em dois lados, como criou uma série de preconceitos e discriminações presentes até os dias atuais. A escola serve de palco para termos uma amostra do que, em larga escala, acontece nos vários palcos da vida (doméstica, profissional e afetiva), mas é também um campo de luta e de possibilidade de transformação social.

A categoria "gênero", tributária dos movimentos feministas, veio em resposta aos debates das décadas de 1960 e 1970. O Segundo Sexo, de Simone de Beauvoir, embora 
publicado em 1949, amparou um aprofundamento teórico que foi se fortalecendo a partir dos anos 60, quando não havia ainda muita teorização sobre questões específicas das mulheres e colocou-se em pauta o tema da subordinação daquela que era vista em segundo plano. Adriana Piscitelli (2009, p. 133) destaca:

O Segundo Sexo é considerado precursor do feminismo da "segunda onda", protagonizado por grupos organizados de mulheres, em diversas partes do mundo, a partir da década de 1960. Várias das ideias presentes nesse livro serão retomadas por vertentes que, embora diversas, compartilham algumas concepções centrais. No entanto, ela [a subordinação] é pensada como universal, na medida em que parece ocorrer em todas as partes e em todos os períodos históricos conhecidos.

O debate sobre a universalidade e o caráter excludente da categoria "Homem" estava em voga entre as feministas da "segunda onda". Reivindicavam-se questões consideradas específicas da "Mulher", como o direito sobre o próprio corpo, especialmente em relação à decisão pessoal de se ter ou não filhos, questionando-se, assim, a maternidade compulsória. A máxima feminista da década de 1960 - "Nosso corpo nos pertence"5 - pretendia ser um contraponto à dominação do homem sobre a mulher. Todavia, não foi necessário muito tempo para se perceber a fragilidade que recairia sobre um universal "Mulher", pois as reivindicações das minorias étnicas, negras e indígenas, e das mulheres de classes sociais economicamente desfavorecidas não eram contempladas de maneira satisfatória naquele movimento de mulheres brancas e de camadas médias. Então, a categoria "gênero" surgiu no interior dos debates que começaram a pensar "as mulheres", e não "a mulher" como um universal e, consequentemente, excludente.

No texto fundador "Gênero: uma categoria útil de análise histórica", de Joan Wallach Scott6, a autora afirma: "O gênero é um elemento constitutivo de relações sociais fundadas sobre as diferenças percebidas entre os sexos, e o gênero é um primeiro modo de dar significado às relações de poder" (SCOTT, 1995, p. 86). Estava aberta, dessa forma, a possibilidade de ampliação da categoria "gênero": não mais fechada na oposição entre os sexos, e sim no aspecto relacional e perceptivo das diferenças. Destaco que perceber é um exercício de aprendizagem. A todo momento estamos aprendendo com os outros a perceber as diferenças de tratamento, de gostos, de sensibilidades. E a percepção também se exercita e se aprende na criação e na análise das narrativas históricas, sejam elas escritas ou pictóricas.

Um desdobramento do aspecto da subordinação cultural que as mulheres enfrentam apresenta-se no senso comum que insiste na ideia de que as questões de gênero estão para as mulheres, ou para as minorias LGBT (Lésbicas, Gays, Bissexuais e Travestis, ou ainda o T podendo representar transsexuais, transgêneros - a sigla já não comporta todas as 
classificações, como intersexos, crossdressers, etc.) - pessoas que se identificam com o feminino, em geral -, o que normalmente é intencionado a limitar e diminuir um campo de conhecimento já consagrado. Esse é um preconceito que tem a ver com o que Thomas Laqueur (2001, p. 32) discute sobre o corpo do homem, cuja tradição cultural construiu uma história sobre a qual esse assunto não havia sido pensado. Todavia, os estudos de gênero sobre masculinidades vêm desconstruindo isso e mostrando que tudo o que se associa ao masculino - como força, bravura, resistência, coragem, rusticidade - é também fruto de construções culturais. Vale citar como exemplo, na historiografia brasileira, as pesquisas de Durval Albuquerque Júnior (2001), que discutem a perda dos espaços de poder e a ruína de um padrão de sociabilidade que vinha desde a colônia, na região Nordeste, e que acabou por criar sentidos de masculinidade, mesmo para mulheres.

No entanto, se o uso da categoria "gênero" permitiu que pesquisadores/as valorizassem as relações entre homens e mulheres e, sobretudo, analisassem como em diferentes momentos do passado as tensões e os acontecimentos produziram o gênero, no ambiente escolar essas discussões ainda são pouco assimiladas. Nos livros didáticos, em especial, a grande maioria dos que se destinam à disciplina de História para o Ensino Fundamental raramente focaliza as mulheres ou o gênero de maneira relacional fora do padrão heteronormativo. Quase sempre, a figura masculina se sobrepõe à feminina e as imagens de mulheres aparecem frequentemente associadas a estereótipos da subserviência e submissão. É raro ver mulheres protagonistas ou valorizadas nas atividades comuns da subsistência (na criação dos/as filhos/as e no trabalho doméstico, por exemplo). Essa grande maioria silenciada passa despercebida, como se tais ações não fossem importantes para a história.

\section{A pesquisa com quadros históricos}

A pesquisa com os quadros históricos de Moacyr Freitas teve início em 2014, durante meu estágio pós-doutoral na Universidade Federal Fluminense (UFF). Atualmente, noutro desdobramento mais específico, sobre a história de Mato Grosso, a investigação focaliza os quadros históricos de Moacyr Freitas que fazem parte do acervo da Secretaria de Estado de Cultura de Mato Grosso (SEC-MT), sob a tutela do Museu Histórico de Mato Grosso. Moacyr Freitas é cuiabano, nascido em 7 de julho de 1930. Formou-se em Arquitetura em 1960, pela Faculdade Nacional de Arquitetura e Urbanismo da Universidade do Brasil, no Rio de Janeiro, e também é escritor e desenhista. Começou a pintar após sua aposentadoria, em 1991, 
quando também entrou para o Instituto Histórico e Geográfico de Mato Grosso. A Secretaria de Cultura tem em seu acervo mais de 60 obras do artista pintadas entre 1999 e 2001, graças a um projeto de autoria do autor com Paulo Pitaluga, cujo resultado parcial foi publicado também em catálogo (SILVA; FREITAS, 2002). Os quadros foram organizados de acordo com a cronologia temática, da colonização do Estado até a proclamação da República. O conjunto de telas foi exposto recentemente (entre junho e setembro de 2016) no foyer (salão de entrada - "Galeria Lava Pés") da SEC-MT, onde a comunidade local pôde apreciá-las. Vinte e duas imagens do acervo foram reproduzidas no livro didático de Elisabeth Siqueira, História de Mato Grosso (2002), e foi o contato com ele que me levou à busca do acervo. O livro é bastante conhecido nos meios escolares e é referência para aqueles que se preparam para os concursos públicos estaduais em Mato Grosso, mas infelizmente as reproduções dos quadros de Moacyr Freitas não serão publicadas em sua nova edição, já no prelo. O acervo tem pouca visibilidade devido ao espaço restrito do Museu Histórico, que expõe de maneira temporária e rotativa cerca de $20 \%$ das obras por vez.

Um dos objetivos da pesquisa é criar mecanismos de aproximação da sociedade cuiabana e mato-grossense com essas telas e, por conseguinte, com a história do estado. Nesse sentido, além deste artigo e outras atividades resultantes do trabalho realizado em 2016, foi desenvolvida uma oficina ${ }^{7}$ ministrada para alunos da graduação em Licenciatura de História em que se apresentaram construções sociais de gênero expostas em cinco quadros do artista (apresentados em slides). A apresentação desencadeou o debate sobre metodologias e didáticas que professores podem utilizar para favorecer a aproximação dos estudantes com as obras de arte munidos de um olhar mais investigativo e questionador. A oficina rendeu numerosas discussões e fomentou a inquietação acerca da carência de contato que estudantes, tanto do ensino básico como superior, têm em relação aos museus da cidade. Noutro momento, em 15 de junho de 2016, realizou-se um trabalho explanatório com funcionários do museu e estudantes de graduação aproveitando a exposição dos quadros na Secretaria de Cultura. A intenção era incentivar, através da Educação Patrimonial e do estudo iconográfico, uma aproximação e interação com a narrativa histórica dos quadros. Nessas oportunidades, identificamos os aspectos de feminilidades presentes nos quadros e como os gêneros estão representados, o que possibilitou questionar as formas hierárquicas de poder neles evidenciadas. Seja nos espaços museais ou de exposição artística, o propósito era estimular o caráter educativo desses locais, como sugere Francisco Régis Ramos (2004, p. 20-21): 
se necessário desenvolver programas com o intuito de sensibilizar os visitantes para uma maior interação com o museu. Não se trata da simples "formação de plateia", a valorização do museu como forma de criar "cultura mais refinada". Antes de tudo, objetiva-se o incremento de uma educação mais profunda, envolvida com a percepção mais crítica sobre o mundo do qual fazemos parte e sobre o qual devemos atuar de modo mais reflexivo.

Esse modo reflexivo evoca pensar também em como se constroem as narrativas históricas. Os quadros se constituem também como narrativas de histórias que se quer contar de determinadas maneiras, com escolhas de personagens e ausências, maneiras de apresentálas, acento de luzes e cores, planos e perspectivas. Como na acepção de Jacques Le Goff (2003, p. 538), são documentos verdadeiros e falsos - falsos "porque um monumento é em primeiro lugar uma roupagem, uma aparência enganadora, uma montagem. É preciso começar por desmontar, demolir esta montagem, desestruturar esta construção e analisar as condições de produção dos documentos-monumentos".

A narrativa pictórica, assim como a literária, serve-se de um processo de construção, segue regras, influências, faz citações e apresenta modelos. No conjunto do acervo de pinturas de Moacyr Freitas, percebe-se que existe uma filiação a uma história mais tradicional, cujo esteio decorre da vinculação ao Instituto Histórico e Geográfico, que desde meados do século XIX tem recorrentemente seguido um tipo de narrativa que representa o Estado nacional a partir de suas elites.

A seguir são destacadas duas personagens da pesquisa. Do conjunto de 60 telas, apenas duas trazem mulheres como protagonistas: A paz com os Guayacurus (Figura 2), com a "Negra Vitória" no fato de 1790, e Rosa Boróro (Figura 4), no fato de 1886 - um outro quadro faz contraponto com esse segundo.

\section{A Vitória}

O quadro intitulado A paz com os Guayacurus é o único do acervo estudado, entre as temáticas do período colonial, que traz uma negra: Vitória. A pintura retrata um suposto acordo de paz entre a Capitania de Mato Grosso e indígenas, que teria sido intermediado por essa personagem central. O acontecimento sucedeu-se em 1790, mas a historiografia regional pouco destaque deu ao episódio ocorrido durante o governo de João Albuquerque - em geral lembrando do capitão-general apenas como "pacificador" de índios, diferente do que relata o viajante cientista Alexandre Rodrigues Ferreira. Uma parte das memórias desse viajante cita “[...] 'uma negra crioula nossa' chamada Vitória, que os cavaleiros haviam capturado como 
escrava e que então lhes servia de 'língua", conforme referência de Maria de Fátima Costa (2001, p. 1009).

Pelos registros de Alexandre Ferreira, seria possível ver outra cena, pois ele relata ter encontrado o líder Guaicuru Caimã, sua esposa e outros indígenas em Vila Bela, região do conflito de fronteira entre portugueses e espanhóis, para assinar o documento, o qual o próprio Alexandre firma como testemunha, reconhecendo a soberania da rainha Dona Maria I sobre o território lusitano (COSTA, 2001, p. 1010-1011). A representação de Moacyr Freitas omite o protagonismo da esposa do chefe indígena na assinatura do "tratado de paz". Havia pelo menos uma década que esse acordo era negociado.

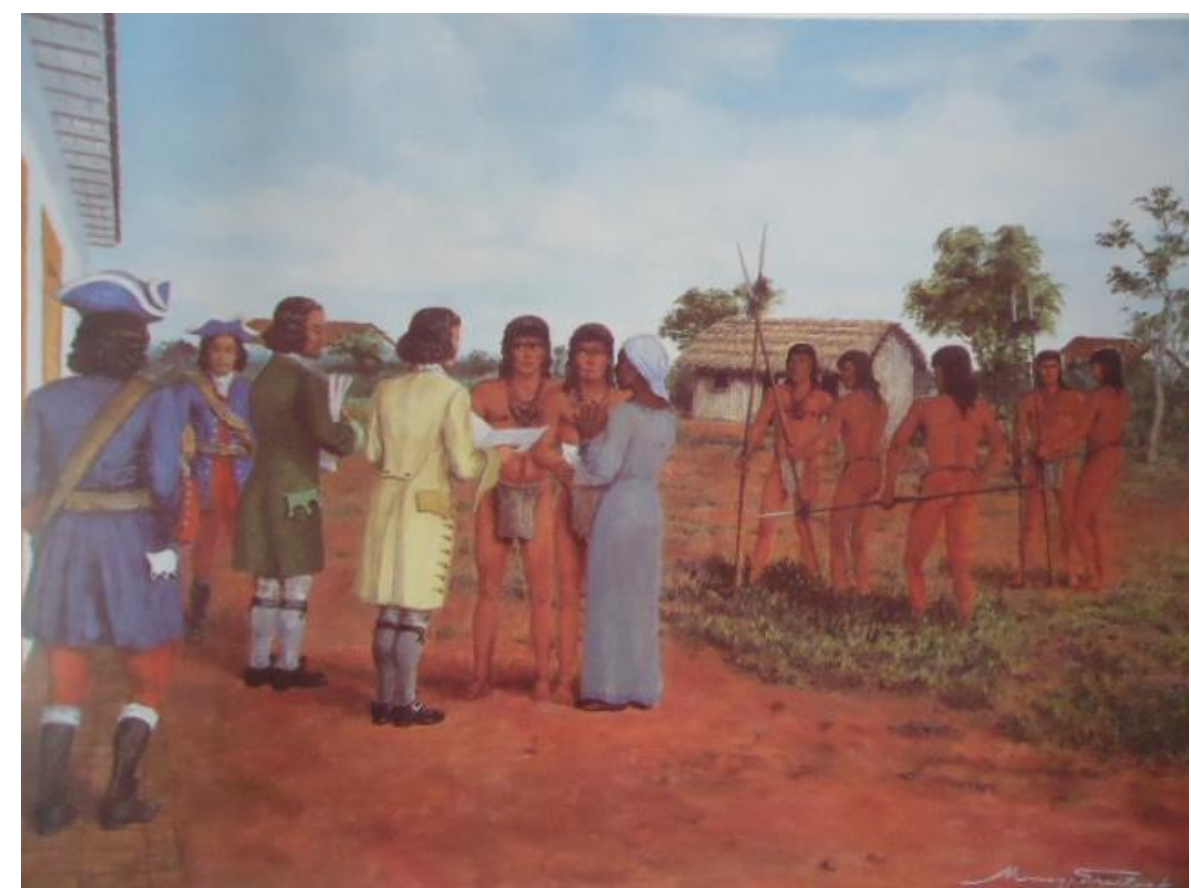

Figura 2 - A paz com os Guayacurus, de Moacyr Freitas, 2000, acrílica sobre tela, $80 \mathrm{~cm}$ x $60 \mathrm{~cm}$ Acervo do Museu Histórico de Mato Grosso.

A protagonista negra, escrava capturada pelos soldados, exerce uma função reveladora de estreita ligação entre negros e índios naquela região, servindo naquele contexto de intérprete bilíngue. A presença das três raças nesse quadro mostra, também, a idealização na construção das categorias raciais, produzindo em certa medida racismo e sexismo, pois estabelece hierarquias procurando sobrepujar as condições sociais que diferenciam grupos sociais pela raça, classe social e condições de gênero. Nessas representações, mesmo quando negros ou índios têm o protagonismo, o "branco", de maneira recorrente, é o que tem propriedades, pensamento e força. A negra, na posição do quadro como personagem central, divide a cena com o personagem indígena - liderança masculina - que aparece de frente. Os 
índios e a negra Vitória estão descalços - o que reforça uma ligação direta com a natureza, entendida como contrária à razão num pensamento cartesiano. O ambiente externo também salienta a ligação desses grupos étnicos com a natureza - tanto que o "acordo" não é representado sendo firmado em uma mesa ou uma sala, local formal em que comumente tem lugar. De maneira recorrente a natureza aparece como aquela que deve ser dominada pela razão e pela força do homem branco.

Ely Bergo de Carvalho (2014, s.p.), em estudo sobre livros didáticos (que ele chama de "livros de divulgação da História de Mato Grosso") ressalta como a "natureza" é reconhecida:

Rios, mosquitos, densa floresta e indígenas eram inimigos a ser vencidos para transformar alguns personagens em "heróis civilizadores". Outra forma como a natureza era significada nos livros em tela era pelo silenciamento. É importante constar que, mesmo sendo um material ligado a um discurso nacionalista e ufanista regional, não havia uma representação de exaltação romântica da natureza nas páginas dos livros de divulgação da História de Mato Grosso de autores ligados ao IHGMT, de forma que seria esperada uma exaltação da natureza mato-grossense nas páginas dos livros citados. No entanto, praticamente não há tal elemento nos livros. As narrativas e a iconografia dos livros são basicamente urbanas. Diante da pecha de lugar incivilizado, os livros mostravam um mundo urbano.

Vale também ressaltar que houve uma escolha para compor esse acervo que conta a história de Mato Grosso através de pinturas. Decidiu-se por destacar uma escrava e silenciouse o protagonismo de Tereza de Benguela, por exemplo, que foi líder negra do Quilombo Quariterê, principalmente destacada depois da morte do seu conselheiro José Piolho, na região de Vila Bela. A história da Rainha Teresa foi relembrada em 1994 pela escola de samba Unidos da Viradouro, tendo à frente o carnavalesco Joãosinho Trinta. Sobre o episódio do quilombo, Freitas espalhou escuridão e anonimato, como no quadro intitulado Destruição do Quilombo Piolho (Figura 3), que apresenta homens negros só de calça de algodão enfileirados em perspectiva decrescente num cenário de natureza escura, céu avermelhado, cor de fogo, onde sobrevoa um urubu, como que anunciando tratar-se de moribundos capturados pelos soldados do governo, em seus uniformes azuis empunhando as baionetas. Do quadro omitiuse não só o protagonismo da liderança feminina, como até o nome de um homem foi destacado para tratar do quilombo. 


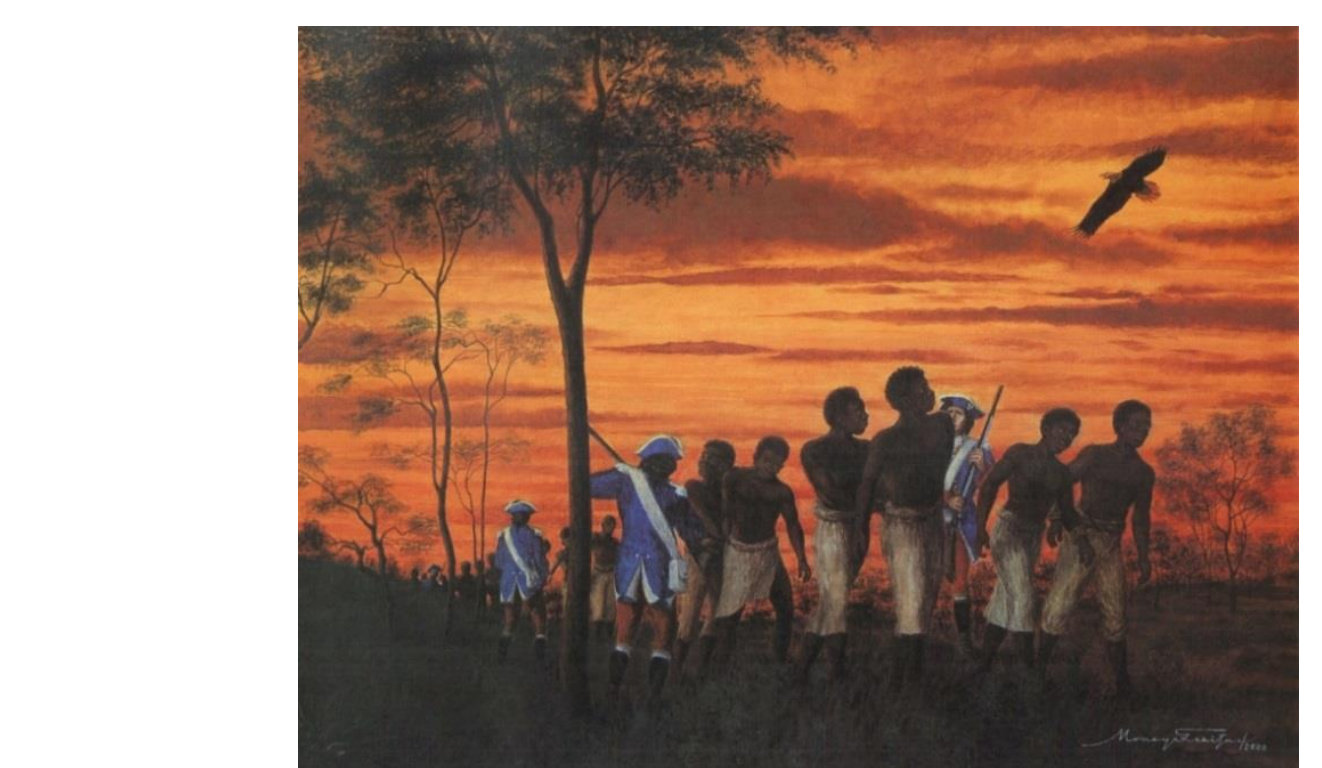

Figura 3 - Destruição do Quilombo do Piolho, de Moacyr Freitas, 2000, acrílica sobre tela, $80 \mathrm{~cm}$ x $60 \mathrm{~cm}$. Acervo do Museu Histórico de Mato Grosso.

O protagonismo negro, através da Vitória, é então, indireto. Ela aparece como importante mediadora, mas a ação que o autor ${ }^{8}$ escolheu foi em favor dos brancos. Ao tratar do tema escravidão elegeu a derrota no quadro sobre o quilombo mais "famoso" (VOLPATO, 1993, p. 184) por sua pujança, número e resistência entre os quilombos de Mato Grosso - o Quariterê:

[...] seus habitantes desenvolviam agricultura diversificada, cultivando, além de gêneros de abastecimento, algodão e fumo. Trabalhavam com ferro e fabricavam tecidos grosseiros. A forma de governo adotada era a realeza e, quando esse foi vencido em 1770, era governado havia 27 anos pela rainha Teresa de Benguela.

Sobre a expedição de 1770, há registro de que entre cerca de 100 pessoas, 30 eram índios (VOLPATO, 1996, p. 222). E, passados 25 anos de resistência, até o ataque de outra bandeira, foram presas 54 pessoas, das quais 30 eram mulheres (índias e Caburés) (VOLPATO, 1996, p. 224), diferente do que mostra o quadro da "destruição" de Moacyr Freitas. Essa presença indígena frequente nos relatos sobre quilombos é também prova da aproximação e miscigenação interétnica.

\section{A Rosa}

O quadro Rosa Boróro, único do período imperial do acervo de Moacyr Freitas cujo protagonismo é dado a uma mulher, representa um suposto acordo entre os militares da Província de Mato Grosso e indígenas Bororos Coroado. 
Marli Auxiliadora de Almeida cita um relato do diretor-geral de Índios Thomaz Antonio de Miranda ao presidente da província José Joaquim Ramos Ferreira ${ }^{9}$ sobre a captura de indígenas:
A V. Excia, não é estranho que há anos, há muitos anos, os nossos lavradores e fazendeiros eram vítimas das correrias dos Coroados, contra os quais expedição - forças armadas para afugentá-los das imediações dos povoados, e essas forças conseguiram apreender algumas índias e crianças. Em 1881, quando se recolheram, as forças expedidas pelo então presidente - Visconde de Maracaju, trouxeram algumas prisioneiras, das quais tomei uma índia, que fiz batizar com o nome Rosa, e depois de quase cinco anos em meu poder e preparada completamente para o fim que tinha em vista, fiz seguir acompanhada de algumas outras para o sertão, como intérpretes, para aliarem os índios bravos de sua tribo, e trazendo em resultado a submissão total dessa numerosa nação (apud ALMEIDA, 2003, p. 3, grifos da autora).

Rosa foi o nome luso-cristão dado a Cibáe Modojebádo. Também outros nomes portugueses foram dados às suas filhas: Rita e Rosália, apadrinhadas pelo mesmo diretor-geral de Índios e sua esposa. Cibáe, como muitas outras índias, foi batizada e tratada para se adaptar à cultura branca. Alguns autores interpretam como adoção, mas de fato nunca tiveram o mesmo status de filhas legítimas. Em geral, as índias eram tratadas como uma propriedade da família que as capturava nas "correrias" ou "pegas a laço", como enfatiza Cristina Wolff (2003): 'Numa sociedade recém-saída da escravidão, era considerado legítimo 'criar' uma criança índia, educando-a como 'criada', encarregada dos múltiplos serviços da casa e seus arredores”. Foi dado um propósito para a índia nomeada Rosa que estava longe de considerála filha, e sim mais para soldado. Estevão de Mendonça (1973, p. 61) confirma: "India Rosa foi a principal auxiliar do alferes Antonio Thomaz de Miranda Rodrigues”.

O alferes Antonio José Duarte, comandante da expedição de 1881 que capturou índias e índios, incluindo Rosa, não a considerava boa apaziguadora na expedição de 1886. Conforme relatou ao presidente da província Joaquim Galdino Pimentel, “A índia Rosa, em vez de auxiliar-me, pelo contrário, procurava plantar a desarmonia entre os índios, que eu em ato contínuo destruía. Esta índia não convém regressar e nem merece consideração alguma" (apud ALMEIDA, 2003, p. 3, grifos da autora). Vê-se uma personalidade controversa sobre a qual se fez uma opção romântica de representação pictórica.

No quadro histórico, Rosa está representada ao lado do cacique, que empunha um arco ornamentado por penas. Percebe-se que os militares estão em desfavorável contingente e já se encontram com armas empunhadas, demonstrando uma suposta insegurança em relação à enorme quantidade indígena. Rosa está retratada como mediadora do acontecimento, contudo é notável que o acordo é feito por homens, sendo a mulher, mais uma vez, um não-sujeito do 
acontecimento, ou seja, ela participa, é importante, mas não faz por decisão própria. Das pinturas observadas, é a única que retrata a mulher como heroína por ter protagonizado a "pacificação", todavia ainda tem seu protagonismo afetado pelo sentido patriarcal da autoridade masculina.

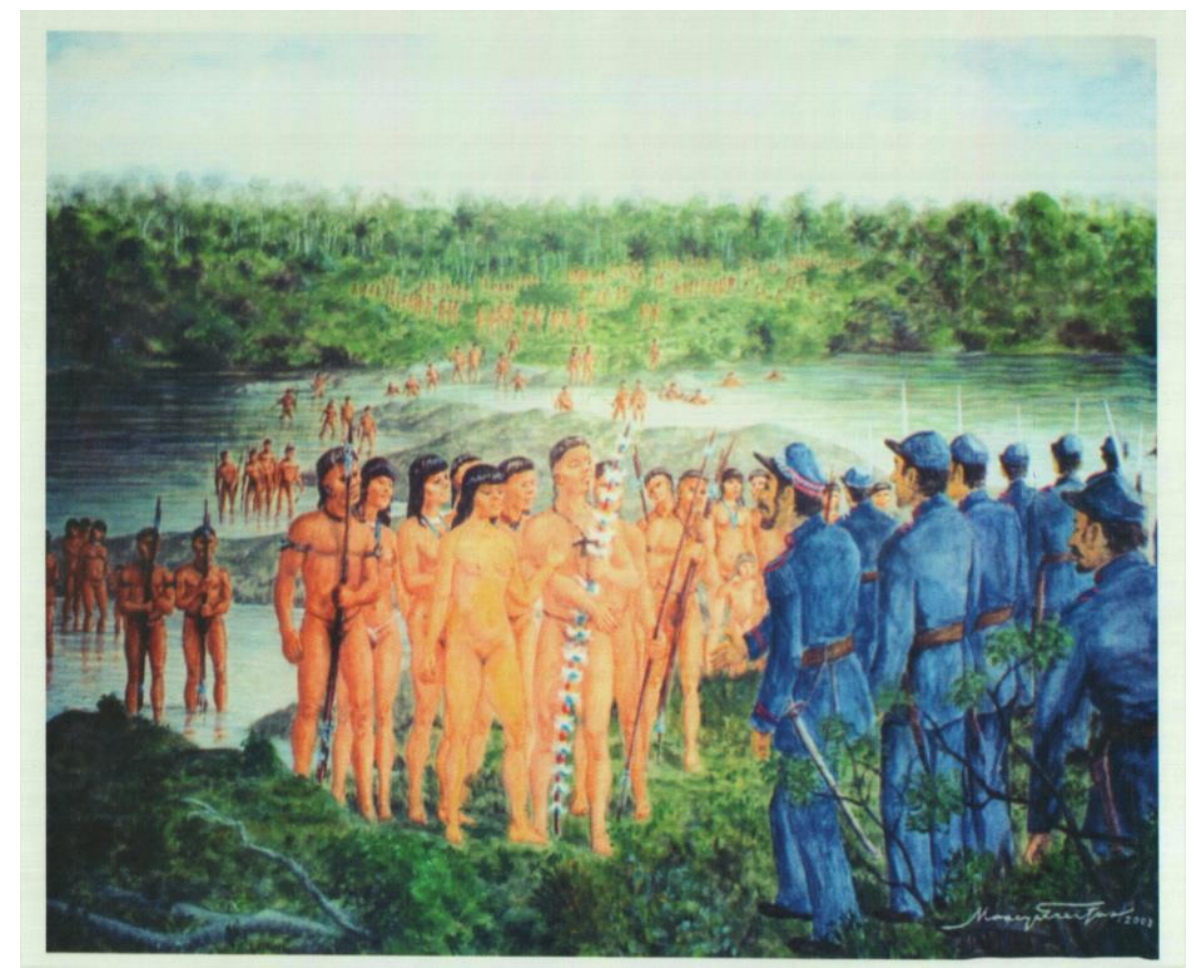

Figura 4 - Rosa Boróro, de Moacyr Freitas, 2000, acrílica sobre tela, $80 \mathrm{~cm} \mathrm{x} 60 \mathrm{~cm}$. Acervo do Museu Histórico de Mato Grosso.

Marli Almeida conta que a representação da Rosa "pacificadora" surgiu em 1895, em uma crônica de Maria do Carmo de Mello Rego, esposa do então presidente da província Francisco Rafael de Mello Rego. Na interpretação romântica ${ }^{10}$ da cronista: "Rosa, radiante de felicidade, por ver terminado a cruel guerra de perseguição e extermínio feita aos seus, tornou a vestir as roupas que deixara e lá ficou prestando relevantíssimos serviços, na primeira trica das novas relações, e fora abençoada mensageira" (apud ALMEIDA, 2003, p. 5, grifos da autora).

Segundo Estevão de Mendonça (1973, p. 62), depois de capturada Rosa estava “Adaptando-se à vida civilizada, mostrava-se agradecida à mão bem-fazeja que cuidava de sua graciosa filha", mas em 1886 já a filha teria morrido de uma "grave doença". Ao fim da vida, "esquecida e abandonada", Rosa teria recomendado a um filho que nunca confiasse nos brancos. 


\section{Considerações}

O artigo pretendeu oferecer elementos para uma crítica a respeito da falta de participação das mulheres nas mudanças políticas e, mais ainda, da ausência de protagonismo quando elas são negras ou índias. Elas pouco ou quase nunca aparecem nas narrativas da História e nas imagens reproduzidas em pinturas de quadros históricos. Como disse Peter Burke (2004, p. 234), "as imagens são testemunhos dos arranjos sociais passados e acima de tudo das maneiras de ver e pensar o passado". Até o início do século XX, os quadros históricos eram formas eloquentes de ensinar História. A maioria da população não era letrada e a reprodução das imagens em livros didáticos era rara. Na medida em que os livros foram reproduzindo obras de grandes mestres da pintura em forma impressa, e atualmente por meio digital e multimídias, foi possível acessar tais obras com mais facilidade e confrontá-las com outras narrativas históricas.

Por meio das análises realizadas, percebemos como as pinturas e diversas historiografias reforçam os estereótipos do feminino. No acervo das telas de Moacyr Freitas como um todo, é visível o papel secundário que a mulher representa, além de funções recorrentes, como a maternidade e o cuidado com o lar. Logo, todas as subjetividades ressaltadas neste trabalho são fundamentais para que a forma como as mulheres são apresentadas sejam discutidas e problematizadas, principalmente em ambientes de formação, como escolas, museus e universidades.

A violência colonizadora não só produz o apagamento de personagens, como as heroiciza por ações que se contrapunham às suas culturas originárias com a pretensão de homogeneizá-las, desconsiderando as relações interétnicas e as diferenças que produzem. As implicações de gênero tornam ainda mais perversas as formas de violência que transformam assassinos e estupradores em promotores de limpeza étnica, agentes de pacificação e varões da miscigenação. A força homogeneizadora do dominador produz também as protagonistas que lhe são convenientes dentro de certas narrativas históricas que precisam ser mais questionadas.

\section{Referências}

ALBUQUERQUE JR. Durval Muniz de. Limites do mundo: a relação entre identidades do gênero e identidades espaciais no Nordeste no começo do século. História: Questões \& Debates, Curitiba, ano 18, n. 37, p. 89-103, 2001. 
ALMEIDA, Marli. Cibáe Modojebádo - a Rosa Bororo e a "pacificação" dos bororo coroado (1845 - 1887). In: Anais do XXII Simpósio Nacional de História - ANPUH, - João Pessoa, 2003. Disponível em: <http://anais.anpuh.org/wpcontent/uploads/mp/pdf/ANPUH.S22.501.pdf>. Acesso em: 20 jan. 2016.

BURKE, Peter. Testemunha ocular: história e imagem. Bauru: Edusc, 2004.

CARVALHO, Ely Bergo de. A quem serve a História? Livros de popularização da História de Mato Grosso, Brasil, 1990-2012. Revista de História Iberoamericana. Vol. 7. n.2. 2014.

COSTA, Maria de Fátima. Alexandre Rodrigues Ferreira e a capitania de Mato Grosso: imagens do interior. História, Ciências, Saúde-Manguinhos, v. VIII (suplemento), 2001.

LAQUEUR, Thomas. Inventando o sexo: corpo e gênero dos gregos a Freud. Rio de Janeiro: Relume Dumará, 2001.

LE GOFF, Jacques. História e memória. 5. ed. Campinas: Editora Unicamp, 2003.

LUGONES, María. Colonialidad y género: hacia un feminismo descolonial. In: MIGNOLO, Walter et al. Género y descolonialidad. 2. ed. Ciudad Autónoma de Buenos Aires: Del Signo, 2014.

MARQUES, Ana Maria Marques. Feminismos e gênero: uma abordagem histórica. Trilhas da História, Três Lagoas, v. 4, n. 8, jan./jun. 2015.

MENDONÇA, Estevão. Datas matogrossenses. 2. ed., 1973. V. II.

PEDRO, Joana Maria. Traduzindo o debate: o uso da categoria gênero na pesquisa histórica. História, São Paulo, v. 24, n. 1, p. 77-98, 2005.

PISCITELLI, Adriana. Gênero: a história de um conceito. In: ALMEIDA, Heloisa Buarque de; SZWACO, José Eduardo (Org.). Diferenças, igualdades. São Paulo: Berlendis \& Vertecchia, 2009.

RAGO, Margareth. Epistemologia feminista, gênero e história. In: PEDRO, Joana; GROSSI, Miriam (Org.) Masculino, feminino, plural. Florianópolis: Mulheres, 1998.

RAMOS, Francisco Régis Lopes. A danação do objeto. O museu no ensino de história. Chapecó: Argos/CEOM, 2004.

SCOTT, Joan W. Gênero: uma categoria útil de análise histórica. Educação e Realidade, Porto Alegre, v. 20, n. 2, p. 5-22, jul./dez., 1995.

SILVA, Tomaz Tadeu da. A produção social da identidade e da diferença. In: SILVA, Tomaz Tadeu da (Org.). Identidade e diferença: a perspectiva dos Estudos Culturais. Petrópolis: Vozes, 2000.

SILVA, Paulo Pitaluga Costa; FREITAS, Moacyr. Quadros históricos de Mato Grosso: período colonial e imperial (Vol.1 e 2). Cuiabá: Editora Buriti, 2002.

SIQUEIRA, Elizabeth Madureira. História de Mato Grosso: da ancestralidade aos dias atuais. Cuiabá: Entrelinhas, 2002.

VALIM, Patrícia. Maria Quitéria vai à guerra. In: FIGUEIREDO, Luciano (Org.). História do Brasil para ocupados. Rio de janeiro: Casa da Palavra, 2013.

VOLPATO, Luiza R. R. Cativos do sertão - vida cotidiana e escravidão em Cuiabá em 18501888. São Paulo/Cuiabá: Marco Zero/EdUFMT, 1993. 
Quilombos em Mato Grosso: resistência negra em área de fronteira. In: REIS, João José; GOMES, Flávio dos Santos. Liberdade por um fio: história dos quilombos no Brasil. São Paulo: Companhia das Letras, 1996.

WOLFF, Cristina Sheibe. Mulheres indígenas na construção etno-histórica de Santa Catarina: memórias de um esquecimento. In: Anais do II Seminário Internacional: Educação Intercultural. Gênero e Movimentos Sociais, 8 a 11 de abril de 2003. Disponível em: <http://www.rizoma.ufsc.br/html/403-of2b-st1.htm>. Acesso em: 16 jan. 2016.

\section{Notas}

1 Entretanto, vale ressaltar a importante observação de Kabengele Munanga, em recente conferência no Seminário de Educação 2016 - Saberes e identidades: povos, culturas e educações, na UFMT, no dia 3 de outubro de 2016, ao destacar que a etnografia e outras etnos foram criadas para estudar os não europeus.

2 "O eixo de colonialidade não é suficiente para dar conta de todos os aspectos do gênero" (tradução minha).

3 “ $\mathrm{Na}$ interseção entre 'mulher' e 'negro' existe uma ausência onde deveria estar a mulher negra porque, precisamente, nem 'mulher' nem 'negro' a incluem. A interseção nos mostra um vazio. Por isso, uma vez que a intersecionalidade nos mostra o que se perde, nos deixa a tarefa de reconceitualizar a lógica da interseção para, desse modo, evitar a separação das categorias dadas e a noção categorial. Só ao perceber gênero e raça como entremeados ou fusionados indissociavelmente, podemos ver realmente as mulheres de cor. Isso implica que o termo 'mulher' em si, sem especificação da fusão, não tem sentido, ou tem um sentido racista, já que a lógica categorial historicamente selecionou somente o grupo dominante, as mulheres burguesas brancas heterossexuais, e portanto escondeu a brutalização, o abuso, a desumanização que a colonialidade do gênero implica" (tradução minha).

${ }^{4}$ Sobre as ondas do feminismo escrevi mais no artigo: MARQUES, Ana Maria. Feminismos e gênero: uma abordagem histórica. Trilhas da História, Três Lagoas, v. 4, n. 8, p. 6-19, jan./jun 2015.

${ }^{5}$ Lucila Scavone traz essa discussão do primeiro momento do movimento feminista, baseado na noção de diferença e criando uma ideia de liberdade e autonomia das mulheres, associada a uma concepção de conhecimento e reapropriação do próprio corpo: SCAVONE, Lucila. Anticonceptión, aborto y tecnologías conceptivas: entre la salud, la ética y los derechos. In: SCAVONE, Lucila (Org.). Género y salud reproductiva en América Larina. Cartago: Libro Universitario Regional, 1999. p. 25-31.

${ }^{6}$ Joan W. Scott é historiadora norte-americana, professora da Escola de Ciências Sociais do Instituto de Altos Estudos de Princeton, Nova Jersey. Especializou-se em História Social Francesa. Na França, lançou algumas publicações sobre história das mulheres, na década de 1980. O texto citado foi primeiramente publicado, no Brasil, na revista Educação e Realidade, Porto Alegre, v.16, n. 2, p. 5-22, jul./dez. 1990. Depois, em outro volume, a revista (v. 20, n. 2, p. 71-99, jul./dez. 1995) publicou o mesmo artigo revisado com consulta ao original inglês. A primeira tradução, de Guacira Lopes Louro, 1990, foi elaborada a partir da versão francesa. A segunda publicação foi revisada do inglês por Tomaz Tadeu da Silva. Este artigo foi publicado originalmente em 1986, no volume 91 da American Historical Review, sob o título Gender: a useful category of historical analysis, preparado para ser apresentado na reunião da American Historical Association, realizada em Nova York, em 1985. Este texto foi traduzido para diversas línguas e causou grande impacto entre historiadores e estudiosas de gênero, em diferentes países. Apesar de já ter completado 18 anos, o artigo continua sendo uma leitura fundamental para aqueles que se dedicam a pesquisas relacionadas ao tema.

${ }^{7}$ III Encontro Estadual de Ensino de História e II Encontro Centro-Oeste de História e Estudos de Gênero: Ensino de História, Relações de Gênero e Arranjos Familiares, ocorridos na UFMT, em Cuiabá, no dia 23 de junho de 2016. A oficina foi orientada por mim e coordenada pela bolsista de Iniciação Científica Karla Ribeiro Gabriel Mesquita e outra bolsista do PIBID (Programa de Iniciação à Docência), Márcia Gabrielle da Silva Almeida.

${ }^{8}$ Existe a compreensão de que a autoria estivesse compartilhada com Paulo Pitaluga, que junto com Moacyr Freitas idealizou as cenas para os quadros, todavia estou considerando autor quem pintou.

9 Informações complementares do documento citado: Diretoria Geral dos Índios. Ofício n ${ }^{\circ} 141$. Documento avulso. 1887. Arquivo Público de Mato Grosso. Lata 1887-G. 
${ }^{10}$ Sem aprofundar, é importante assinalar que o romantismo foi um gênero literário que marcou a segunda metade do século XIX. No Brasil, um dos representantes exemplares de um chamado romantismo indianista foi José de Alencar, cuja obra literária Iracema (1865) foi interpretada em 1881 na pintura de José Maria de Medeiros, reproduzida em várias edições do livro. A imagem traduz a personificação da pureza no elemento indígena que se queria afirmar nas características identitárias da nação à época. 